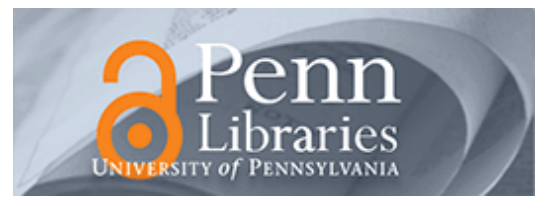

University of Pennsylvania ScholarlyCommons

October 2007

\title{
Intervention on Behalf of Children Exposed to Intimate Partner Violence: Assessment of Support in a Diverse Community-based Sample
}

Susan B. Sorenson

University of Pennsylvania, sorenson@sp2.upenn.edu

Follow this and additional works at: https://repository.upenn.edu/spp_papers

\section{Recommended Citation}

Sorenson, S. B. (2007). Intervention on Behalf of Children Exposed to Intimate Partner Violence: Assessment of Support in a Diverse Community-based Sample. Retrieved from https://repository.upenn.edu/spp_papers/80

Postprint version. To be published in Child Abuse \& Neglect, Volume 31, Issue 11-12, November 2007, pages 1155-1168.

This paper is posted at ScholarlyCommons. https://repository.upenn.edu/spp_papers/80

For more information, please contact repository@pobox.upenn.edu. 


\title{
Intervention on Behalf of Children Exposed to Intimate Partner Violence: Assessment of Support in a Diverse Community-based Sample
}

\begin{abstract}
Although children exposed to intimate partner violence (IPV) are at an increased risk of psychological, behavioral, and physical health problems, whether to intervene on their behalf remains a controversial issue. Policymakers and community service professionals would benefit from understanding public support for such intervention as well as any contexts or demographics associated with variation in that support. Such professionals could use this information to: 1) predict better the public's support for funding interventions and potential involvement in reporting cases or encouraging families to seek help, and 2) aid in the development of criteria for a differential intervention response for children exposed to IPV based on the severity of IPV cases.
\end{abstract}

\section{Keywords}

child maltreatment, intimate partner violence, intervention, public opinion, community-based norms

\section{Comments}

Postprint version. To be published in Child Abuse \& Neglect, Volume 31, Issue 11-12, November 2007, pages $1155-1168$. 
Intervention on Behalf of Children Exposed to Intimate Partner Violence:

Assessment of Support in a Diverse Community-based Sample

Catherine A. Taylor ${ }^{1}$ and Susan B. Sorenson ${ }^{2}$

${ }^{1}$ Tulane University School of Public Health and Tropical Medicine, Department of Community Health Sciences, New Orleans, LA

${ }^{2}$ University of Pennsylvania School of Social Policy and Practice, Philadelphia, PA

Correspondence \& reprint requests should be addressed to: Catherine A. Taylor, MSW, MPH, $\mathrm{PhD}$, Tulane University School of Public Health and Tropical Medicine, Department of Community Health Sciences, 1440 Canal St., TW-19, Suite 2301, New Orleans, LA 70112; cat28@cornell.edu; (504) 988-0292 Phone, (504) 988-3540 Fax

Keywords: Child maltreatment; Intimate partner violence; Intervention; Public opinion; Community- based Norms

Acknowledgments: The data used in this research project were obtained through a grant funded by the California Department of Health Services (CDHS). The work reported herein is that of the authors; it is not the work of nor does it represent the official views of CDHS.

The authors would like to thank the members of the community advisory panel (Brenda Aris, Richie Cole, Charles Hall, Alva Moreno, Nilda Rimonte, Rosario Roberts, and Bernita Walker) and the 3,679 California adults who participated in the study.

In press. Child Abuse \& Neglect. Expected release: October 2007. 


\section{Practice Implications:}

Although children exposed to intimate partner violence (IPV) are at an increased risk of psychological, behavioral, and physical health problems, whether to intervene on their behalf remains a controversial issue. Policymakers and community service professionals would benefit from understanding public support for such intervention as well as any contexts or demographics associated with variation in that support. Such professionals could use this information to: 1) predict better the public's support for funding interventions and potential involvement in reporting cases or encouraging families to seek help, and 2) aid in the development of criteria for a differential intervention response for children exposed to IPV based on the severity of IPV cases. 


\begin{abstract}
Objective: The aim of this study is to assess community-based support for intervening on behalf of children exposed to intimate partner violence (IPV) and to determine what contextual and respondent characteristics are associated with that support.
\end{abstract}

Method: An experimental vignette design was used in a random-digit-dial survey of six ethnic groups in California. For each respondent $(n=3,679)$, seven vignettes about IPV were generated using randomized categories of victim and assailant characteristics (i.e., gender and sexual orientation, age, ethnicity, nativity, occupational status, and relationship status) and situational characteristics (i.e., motivation, weapon use, type of abuse, alcohol use, frequency of the incident, and child present). All vignettes analyzed for this manuscript $(n=6,556)$ mentioned that "there was a child in the other room" during the incident.

Results: In $70 \%$ of the IPV scenarios, respondents supported intervention on behalf of the child. Support was lowest when the IPV was purely psychological in nature (62-63\%), higher when it involved threats, coercion, or limited physical abuse (68-71\%), and highest when it involved severe physical abuse (76-81\%). The odds of supporting intervention also were elevated when a weapon was involved, when the IPV occurred multiple times, and when the IPV involved gay men. Men and Vietnamese Americans had the lowest odds of favoring intervention.

Conclusions: Public opinion assessed in this survey is aligned with that of professionals who believe that the potential impact of IPV on children should not be ignored and who have suggested that criteria should be developed to guide a graded intervention response for such cases. 
An estimated 3 to 10 million children are exposed to intimate partner violence (IPV) each year (Carlson, 1984; Straus, 1992). According to data from the Spousal Assault Replication Program, children are over-represented in homes in which IPV has been substantiated, and children under the age of 5 are at greatest risk of exposure to multiple incidents (Fantuzzo, Boruch, Beriama, \& Atkins, 1997; Fantuzzo \& Mohr, 1999). Exposure to IPV has been linked to an increased risk of negative social, emotional, and behavioral outcomes in children (Kernic et al., 2003; Margolin \& Gordis, 2000; McFarlane, Groff, O'Brien, \& Watson, 2003; Wolfe, Crooks, Lee, McIntyreSmith, \& Jaffe, 2003); however, the mechanism of action is unclear. The increased risk that children face may be due to trauma resulting from exposure to IPV, the nature of which may vary substantially (Holden, 2003), or to some critical confounded variable such as physical maltreatment of the child, although a recent meta-analysis of the literature does not lend support to the latter hypothesis (Kitzmann, Gaylord, Holt, \& Kenny, 2003).

Many studies have found that child maltreatment and IPV co-occur at a median rate of about 40\% (Appel \& Holden, 1998; Edleson, 1999). For example, in a nationally-representative sample of investigated child maltreatment cases, the lifetime prevalence of IPV was about $45 \%$, and the past year prevalence was 29\% (Hazen, Connelly, Kelleher, Landsverk, \& Barth, 2004). Most research in this area has not examined the temporal ordering of the phenomena. However, in a longitudinal study of mothers who participated in a child abuse prevention program, the presence of IPV was found to raise the odds of subsequent child abuse and neglect by two to three times (McGuigan \& Pratt, 2001). Thus, although exposure to IPV in and of itself may cause trauma to children, the presence of IPV also may serve as a significant risk factor for future child maltreatment. 
Despite the risks that IPV poses to children, whether or not to intervene on their behalf remains a controversial issue. Should intervention for children occur in all such cases and, if not, what criteria should guide the decision to intervene? There is currently no consensus among the states on this issue. Some states, including Alaska, Delaware, Georgia, and Utah, have introduced legislation that in effect makes exposure to IPV a form of child maltreatment (Christian, 2002). The argument to broaden child maltreatment definitions to include exposure to IPV assumes that such exposure may be considered a form of emotional or psychological maltreatment in and of itself. However, it is debatable whether exposure alone should be considered maltreatment. Some argue that there are many traumas that children may be regularly exposed to for which intervention is not mandated (e.g., community violence, secondhand smoke), and also that there are many intervening factors that are relevant in determining the ultimate impact of IPV exposure on a child (Edleson, 2004).

Another argument goes a step further and considers exposure to IPV a form of child neglect, suggesting that the non-offending caregiver should be charged with "failure to protect." This argument has been criticized for wrongly placing blame and responsibility on the victimized adult and for failing to recognize that this parent may be acting in the child's best interest by not leaving the offending partner (Magen, 1999). When this type of legislation was tested in New York state, the courts ruled in favor of the mothers who were charged under this premise ("Sharwline Nicholson vs. Nicholas Scoppetta et al.," 2004).

In addition to deciding what is in the best interest of these children, there are some practical issues to consider. In 1999, Minnesota expanded its definition of child neglect to include exposure to IPV (Edleson, 2004). Subsequent to this change, Minnesota experienced a substantial increase in reported cases of children exposed to IPV, which created a need for $\$ 30$ 
million in additional services for these children and families. The state, overwhelmed with new reports and unable to meet the increased demand in services, repealed the law in 2000.

Responding to children's exposure to IPV requires an appreciation for the varying contexts of the problem (i.e., the situational factors that might impact outcomes) as well as for the practical issues involved in developing a cost-effective response. Edelson (2004) has urged professionals and researchers to begin to consider and examine the context of the exposure in order to determine which circumstances most warrant intervention for children:

One way to differentiate those requiring a report to child protective services would be to develop a series of criteria and/or screening instruments that, based on available or new data, indicate heightened risk for children. For example, should these criteria include domestic violence occurring with other risk factors such as the presence of weapons; the proximity or actions of the child in violent situations; the presence of an alcohol or drug abusing caregiver; the history of the abusive partner including repeated or severe violence in the home? (p.22)

Magen (1999) similarly asked researchers to consider, “...what is the threshold for intervening [in such cases]? (p. 134).” Experts seem to agree that the issue warrants further attention (e.g., to develop criteria to determine a graded or threshold intervention response) and that these children and their families would likely benefit from some form of community-based services (Edleson, 2004).

In addition to expert opinion, public opinion is relevant to this issue as well. Because a substantial proportion of the public has personally known an IPV victim (Sorenson \& Taylor, 2003) and because IPV is not always detected by authorities, persons in the community may play an important role in encouraging parents who experienced IPV to seek help for themselves and their children. They also may play a role in reporting cases to authorities when needed. Furthermore, knowledge of public support on this issue would aid in garnering the political will needed to make relevant and successful policy, service, and funding changes. It also is important 
to know whether the work of child protective service agencies, who implement implicit community norms that drive decision-making in child maltreatment, is consistent with public opinion. Despite their potential importance to policymakers and community service professionals, public attitudes about aiding children exposed to IPV have not been assessed. Public support for preventing child abuse is high among adults in the U.S. In a 2001 national poll, child abuse was ranked highest among a list of 11 possible national health priorities (Bostrom, 2003). A substantial majority (83\%) of Americans believe that primary prevention of child abuse is possible (Harding \& Fromm, 2000), and $82 \%$ of parents support government funding for such efforts (Daro, 1999). However, there is ambivalence about government intervention as a primary response to child maltreatment: $80 \%$ of a statewide sample believed that the greatest responsibility for intervention belongs in the private domain (i.e., family, friends), yet $69 \%$ believed that government agencies should step in if other efforts fail and the risk of harm to the child is great (Brandon \& Gordon, 1997). Although the prevention of child abuse is generally supported, it is unclear whether intervention on behalf of children exposed to IPV is specifically supported and, if so, under what specific circumstances.

In addition, public opinions about child maltreatment may vary by characteristics of those making the judgments. Some researchers have found respondent ethnic (Rose \& Meezan, 1995) and gender differences in ratings of child maltreatment (Ferrari, 2002), suggesting that public opinion regarding child maltreatment definitions may vary across demographic characteristics. In both studies, however, many potential demographic confounders were not taken into consideration, which indicates the need for further research. 
The current study was undertaken as part of a larger investigation designed to gain a better understanding of community-based judgments, or injunctive social norms, regarding how and under what conditions society ought to respond to IPV. In prior work from this survey, respondents expressed support for interventions including calling police and issuing a restraining order, in a majority of IPV cases (Taylor \& Sorenson, 2004); in addition, support for intervening was highest under certain circumstances, such as when the abuse type was most likely to cause physical injury or when sexual abuse occurred (Sorenson \& Taylor, 2005; Taylor \& Sorenson, 2004). Three questions were the focus of the current study: 1) Does the public support intervention on behalf of children who are present during IPV? 2) What conditions influence the choice to support intervention in such cases? and 3) Are respondent characteristics associated with support for intervening?

Methods

\section{Sample}

The sample of 3,679 California adults contained roughly equal proportions of African Americans (15\%), Hispanics (18\%), Korean Americans (17\%), Vietnamese Americans (17\%), other Asian Americans, not of Korean or Vietnamese descent, (17\%), and Whites (16\%). A substantial proportion of Asian Americans were sampled because California has the largest Asian population of all the states within the continental U.S. (The Asian Population: 2000. Census 2000 Brief). With over-sampling, we expected African Americans, Hispanics, and most Asian Americans, including Filipinos and Chinese Americans (the two largest Asian American sub-groups in CA), to be well-represented via the English language survey. However, we expected Korean and Vietnamese Americans (the third and fourth largest Asian American subgroups in CA) to be under-represented if respondents were not interviewed in their native 
languages. Therefore, we over-sampled these groups and conducted interviews in Korean, Vietnamese, Spanish, and English.

In order to obtain this ethnically diverse sample, a cross-sectional sample of the state of California, collected from a random digit dial (RDD) sampling frame of 29,000 residential telephone numbers, was supplemented with five RDD oversamples from census tracts known to have high concentrations of the non-White populations listed above. This sampling strategy allowed us to make statistically meaningful comparisons across each of the sampled ethnic groups. The overall response rate of $51.5 \%$ was calculated using standards set forth by the American Association of Public Opinion Research.

A majority of the sample was foreign-born (59.9\%) and female (58.8\%), and the median age was 40 years old; $47.3 \%$ were married, and $29.4 \%$ were not in a relationship. Households usually included at least two adults (76.2\%) and less frequently included at least one child age 5 or older $(35.3 \%)$ or under age $5(19.4 \%)$. Of the sample, $53.5 \%$ worked full-time and $60.9 \%$ lived in a large city. The sample included a wide range of education and income levels.

\section{Questionnaire design and study procedures}

A fractional factorial design was used to generate vignettes (i.e., scenarios) that described incidents of IPV. This experimental design allows for the simultaneous assessment of multiple factors and categories as they may be relevant to respondents' judgments, and is well-suited for examining social norms in a large population (Rossi \& Anderson, 1982). Based on a review of the literature and consultation with our community experts panel-comprised of IPV service providers, survivors of IPV, and the creator of a public awareness campaign about rape-12 factors or contexts of potential importance in judging IPV incidents and categories for each were selected for inclusion in the vignettes. The 12 factors were divided equally among victim and 
assailant characteristics and situational characteristics. The six victim and assailant characteristics were gender (same gender combinations were possible), age, ethnicity, nativity, occupational status, and relationship status. The six situational characteristics included motivation for the abuse, weapon use, type of abuse, alcohol use, frequency of the incident, and whether a child was present. Categories from each of these factors were randomly assigned to create a story or vignette about IPV, for example:

June, a 35-year-old Asian American woman is a medical doctor and born in the U.S. She is married to Mike, a White man of the same age who is an office administrator and is also U.S. born. One evening he accused her of disrespecting and shaming him. Then he grabbed an available object in a threatening manner and threatened to harm her. There was a child in the other room. Before this incident occurred, he had nothing to drink and she drank heavily. This was the only time that an incident like this had happened between them.

Seven vignettes were read to each respondent; we determined through pre-testing the questionnaire that subjects could comfortably listen and respond to seven vignettes. This resulted in a vignette sample size of 25,753 (3,679 subjects $\mathrm{x} 7$ vignettes). For the current investigation, analyses included only those vignettes that were randomly assigned the phrase, "There was a child in the other room" $(n=6,556)$. (Although the risk to the child might have seemed direr if the child was in the room where the incident occurred, the human subjects committee advised against using this option, especially when the IPV involved physical or sexual violence. However, comments made during focus groups conducted as a part of questionnaire development suggested that respondents understood the concept of exposure. For example, respondents noted that although the child was in the other room, he or she must have seen or 
heard what was going on.) After each vignette, respondents were asked a series of questions ending with "Should social workers be called to check on the children?" which comprises the dependent variable in the present study.

Information gleaned from focus groups, cognitive interviews and pre-tests was used to revise and refine the questionnaire. The final English-language version of the questionnaire was translated into Spanish, Vietnamese, and Korean, translated back into English, and then minor adjustments were made to ensure equivalency of the forms.

The National Opinion Research Center (NORC) recruited, trained, and supervised interviewers, who then conducted the interviews using Computer Assisted Telephone Interviewing. In an attempt to increase participation, follow-up letters and incentives were used. Letters were mailed to households that were difficult to contact. Incentives were offered to respondents in cases where they initially refused or were reluctant to participate. Once a household was reached, the interviewer asked to speak with "the person who is 18 or older in your household who will have the next birthday." The interviews lasted 27 minutes on average. Data were collected between April 11, 2000 and March 25, 2001.

The Institutional Review Board at the University of California Los Angeles and the Committee on the Protection of Human Subjects' Rights at the University of Chicago for the National Opinion Research Center each reviewed and approved the study protocol. Readers interested in more methodological detail are referred to Dugoni and Baldwin (2000) and Imhof, Murphy, and Moore (2001).

\section{Statistical analyses}

Correlation matrices, frequency distributions, and tests for multicollinearity were examined for all predictors (i.e., all vignette variables manipulated in the design and all measured respondent 
demographic characteristics). Bivariate analyses were used to test for associations between the predictors and the dependent variable. A multivariate logistic regression was conducted to assess the independent effects of each predictor (all previously described vignette variables and respondent characteristics) on the outcome. The robust cluster option in STATA was used in order to account for the non-independence of vignettes—-seven for each respondent.

The effects are reported as adjusted odds ratios (AOR). An odds ratio is an exponeniated regression coefficient; when the logistic regression includes multiple predictors, the odds ratio for each predictor is considered adjusted for the effects of all the other predictors. For example, if the AOR is 2.0 , the odds of the outcome being "yes" (in this study) are twice as great for that category as compared to the reference category, controlling for all other predictor variables in the model. Reference categories for each predictor are referred to in the Table only. A Bonferroni correction for multiple statistical tests was made (Pedhazur \& Kerlinger, 1982); only those findings that exceeded this adjusted level of statistical significance $(\mathrm{p}<0.00044)$ are reported and discussed in the text. However, all results that were significant at $\mathrm{p}<0.05$ are reported in the tables.

\section{Results}

In $70.0 \%$ of the IPV vignettes that included a child, respondents thought that a social worker should be called to check on the children. The range of support was fairly consistent (i.e., variation in level of support was less than $10 \%$ across variable categories) for all but three of the variables (Table 1). Among the vignette variables, the variation in support was widest for "abuse type" (62.2 - 80.9\%) and second widest for "weapon" (64.0-78.5\%). Support was expressed most often when the risk of potential physical harm to the adult victim was greatest, that is, when the victim was punched, raped, or beaten or when a knife or gun was present. 
Support also was consistent across respondent characteristics with one exception - there was a nearly $20 \%$ difference across ethnic groups. Vietnamese Americans were least $(62.3 \%)$ and Hispanics were most (81.3\%) likely to want a social worker to check on the children after an IPV incident.

As shown in Table 2, after taking into account all vignette variables and respondent characteristics, three contexts emerged as substantial predictors of support for intervention: abuse type, weapon availability, and frequency of the incident. The odds of supporting intervention were greater when the victim was beat up, raped, or punched $(\mathrm{AOR}=2.56,2.04$, and 1.86, respectively), when the assailant pulled out a gun or a knife (AOR $=2.11$ and 1.61 , respectively), and when the incident happened for the fifth time or was one of many times (AOR $=1.92$ and 1.73 , respectively). The only other vignette variable that mattered in predicting support was the gender and sexual orientation of the victim and assailant: support for intervention was highest when the violence occurred in a gay male couple $(\mathrm{AOR}=1.76)$.

As shown in the second part of Table 2, two of the measured respondent characteristics, ethnicity and gender, were associated with variation in support for intervention. The odds of support for intervention were lower for Vietnamese Americans than for Whites $(\mathrm{AOR}=0.51)$ and for men than for women $(\mathrm{AOR}=0.75)$. Although these findings are statistically significant, bivariate data suggest that these differences may have little substantive meaning. There was a $5 \%$ difference in support between men and women $(66.7 \%$ vs. $72.3 \%$, respectively, $p=0.000)$ and a 7\% difference between Vietnamese Americans and Whites (62.3\% vs. 69.2\%, respectively, $\mathrm{p}=0.001)$.

\section{Discussion}


In sum, the highest levels of support for intervention on behalf of children exposed to IPV were observed in incidents that involved a high risk of physical harm to the adult victim (i.e., physical abuse or rape, weapons, or chronic abuse) or that occurred between gay men. Few respondent characteristics were associated with variation in support and the variation that was identified may be of marginal substantive significance.

A diverse sample of respondents supported intervention on behalf of children in $70 \%$ of a wide range of IPV scenarios, suggesting that IPV exposure in and of itself is viewed by community members as a substantial threat to a child's well-being. We generally found little evidence for variation in opinion on this issue across population groups. Although respondents' gender and ethnicity were associated with statistically significant variations in support, even the groups with the lowest odds of supporting intervention (i.e., men and Vietnamese Americans) thought that social workers should be involved in over $60 \%$ of the IPV cases. However, the $20 \%$ range of variation across ethnic groups is worth noting and suggests that public opinion about whether to intervene may differ by ethnic heritage. Because foreign-born status was taken into account, cultural values associated with family life or some other factors linked with ethnicity likely drive these findings. (One might hypothesize that length of time in the U.S. is at issue but subsequent multivariate analyses indicated that it is not a relevant factor.)

From both a community practice and a policy development perspective, it is important to note that there was variation in support across certain contexts of the incident. Indicators of elevated risk of physical harm—severe violence, weapon availability, and multiple incidentswere the most important predictors whereas less severe forms of IPV garnered lower levels of support for intervening on behalf of children. These findings suggest that public opinion may be aligned with recent research recommendations (Kitzmann et al., 2003), practice guidelines for 
screening of IPV in child maltreatment cases (Bragg, 2003), and recommendations of the Family Violence Department of the National Council of Juvenile and Family Court Judges (NCJFCJ) on providing differential responses to IPV according to variations in risk. In particular, the NCJFCJ cited the need for a "range of interventions" depending on the severity of the IPV cases: "... To create safety and stability for families requires careful assessment of risk and the capacity to make differential responses" (Schechter \& Edleson, 1999, p 15). Study findings suggest that, independent of other characteristics of the IPV incident, levels of public support for communitybased intervention are highest when the physical safety of the adult victim and the child is most threatened.

An additional relevant context is the gender and sexual orientation of the adult victim: support for intervention on behalf of children was highest when the IPV occurred between gay men. This finding is perhaps not surprising given the substantial bias against gay couples in parenting, particularly in adoption (Lin, 1999; Patterson, 1995). In addition, gay men who are victims of IPV tend to incur more blame, garner less support for therapeutic intervention, and receive greater encouragement to separate than their heterosexual and lesbian counterparts (Davies, Pollard, \& Archer, 2001; Taylor \& Sorenson, 2005). These findings suggest that gay male parents might experience bias in community efforts to intervene and potentially remove children from the home. Vigilance is warranted to ensure fair and unbiased intervention in such cases.

\section{Study strengths and limitations}

The present investigation has several methodological strengths. The sample size of nearly 3,700 respondents and over 6,500 vignettes allowed for the simultaneous examination of multiple contextual and respondent characteristics. Over-sampling multiple ethnic groups, 
measuring variables often related to ethnicity (i.e., nativity, income, educational status), and making the interview available in multiple languages created a highly diverse, community-based sample which allowed for meaningful analyses across social strata. Using an experimental vignette design and multivariate statistical techniques allowed us to examine multiple potentially relevant IPV contexts and to identify those that most influenced respondents' judgments.

Maximizing respondent participation is an increasing challenge in survey research. The response rate of $51.5 \%$ in the current investigation, higher than that obtained in other recent multi-language surveys conducted in the state (California Health Interview Survey, 2002; Weinbaum et al., 2001), is a reflection of that challenge. Response rates have declined substantially during the last two decades, perhaps due to an increased use of call screening devices, multiple uses for telephone lines and an increase in telemarketing (Tuckel \& O'Neill, 2001). In locales such as California where more than one-quarter of the population is foreignborn (U.S. Census Bureau, State and County QuickFacts: California, 2000), language fluency presents a problem; for example, persons who spoke languages other than the four languages in which the interviews were offered could not be screened out as ineligible so remained in the denominator which lowered the response rate. Given the multiple languages spoken in the population, the current challenges faced by all telephone survey research, and the high quality of the data collection agency, the obtained response rate may be the best currently possible.

An important limitation of this study was the use of only one response variable that focused specifically on social work intervention, even though other types of professionals and interventions might be involved and relevant for such cases. Had we inquired about other types of professional involvement on behalf of children (e.g., psychologists, police), varying levels of support might have been found for each type based on opinions about each profession and their 
ability to respond to the needs of children. However, because this was the only interview question that asked about the child specifically, we expected the most salient part of this question to be "...to check on the children." Therefore, we expected the response to be focused primarily on whether or not the children needed some kind of professional assistance rather than on the specific professional providing the assistance. Focus groups conducted as part of questionnaire development suggested that the "social worker" may have been interpreted specifically as a "child protection service worker."

Although the examination of multiple vignette variables is a strength of this study, omitted variables might nonetheless be relevant to public opinion on this topic. In particular, variables associated with a child's risk of harm in the presence of IPV (e.g., the child's age, the co-occurrence of child maltreatment, and level of the child's involvement in the incident (Edelson, 2004)) might also affect public support for intervention. Although there is substantial support in the existing literature for the importance of the nature of the exposure itself on the psychosocial functioning of children, there is little support for child-specific differentials (Kitzmann et al., 2003).

\section{Implications}

Study findings suggest that community members acknowledge that exposure to IPV is detrimental to children. Despite this understanding and agreement, societal response and services historically have not been unified to address effectively the needs of both child and adult victims of IPV (Edleson, 1999; Findlater \& Kelly, 1999). The disparate histories and goals of child welfare and IPV interventions and services have created challenges to designing a comprehensive, coordinated, and tailored response to aiding children exposed to IPV; however, collaborations between such services have grown tremendously in the past decade (Aron \& 
Olson, 1997; Edleson, 1999; Findlater \& Kelly, 1999; Schechter \& Edleson, 1999). Programs such as the Violence Intervention Program for Children and Families (VIP) offer a model for interdisciplinary collaborative efforts to train police, often the first responders to IPV incidents, to be sensitive to the needs of child, as well as adult, victims of IPV (Osofsky, 2004). Findings from the current study suggest that the public would support such interventions on behalf of children.

This public support has practical implications for community service professionals and policymakers alike. Evidence of this public support, along with the support for multiple methods of generating violence prevention funding (Sorenson, 2003), can aid policymakers and professionals seeking to garner the political will needed to increase funding for developing innovative interventions and strategies, such as the aforementioned VIP program. In addition, this survey highlights some key contexts that may be most relevant and most supported in developing criteria for a graded, differential intervention response. Finally, high levels of support for intervention also suggest that community members with personal knowledge of IPV might be engaged to aid in community-based efforts to identify children in need of assistance or encourage intervention for affected children. Policy makers and community-based professionals seeking to improve the well-being of children exposed to IPV may benefit from a better understanding of public support for intervening on behalf these children. 


\section{References}

Appel, A. E., \& Holden, G. W. (1998). The co-occurence of spouse and physical child abuse: A review and appraisal. Journal of Family Psychology, 12(4), 578-599.

Aron, L. Y., \& Olson, K. K. (1997). Efforts by child welfare agencies to address domestic violence: The experiences of five communities. Retrieved Dec. 28, 2004, from http://www.urban.org/url.cfm?ID=406798

The Asian Population: 2000. Census 2000 Brief. Retrieved March 29, 2002, from http://www.census.gov/prod/2002pubs/c2kbr01-16.pdf

Bostrom, M. (2003). Discipline and development: A meta-analysis of public perceptions of parents, parenting, child development, and child abuse. Retrieved August 23, 2004, from http://www.preventchildabuse.org/learn_more/frame_analysis/docs/overview.pdf

Bragg, H. L. (2003). Child protection in families experiencing domestic violence. Washington D.C.: U.S. Department of Health and Human Services, Administration for Children and Families, Administration on Children, Youth and Families, Children's Bureau, Office on Child Abuse and Neglect.

Brandon, R. N., \& Gordon, A. (1997). Public opinion about child protection issues in Washington state (Executive Summary). Human Services Policy Center, University of Washington.

California Health Interview Survey. CHIS 2001 methodology series: Report 4 - response rates. (2002). Retrieved June 18, 2004, from http://www.chis.ucla.edu/pdf/CHIS2001_method4.pdf

Carlson, B. E. (1984). Children's observations of interparental violence. In A. R. Roberts (Ed.), Battered women and their families (pp. 147-167). New York: Springer.

Christian, S. (2002). Children's exposure to domestic violence: Is it child abuse? NCSL State Legislative Report, 27(1). 
Daro, D. (1999). Public opinion and behaviors regarding child abuse prevention: 1999 survey. Chicago, IL: Prevent Child Abuse America, National Cener on Child Abuse Prevention Research.

Davies, M., Pollard, P., \& Archer, J. (2001). The influence of victim gender and sexual orientation on judgments of the victim in a depicted stranger rape. Violence and Victims, 16(6), 607-619.

Dugoni, B. L., \& Baldwin, A. K. (2000). Cognitive lab report, research project (\#4943) on DV vignettes. Chicago, IL: National Opinion Research Center at University of Chicago.

Edleson, J. L. (1999). The overlap between child maltreatment and woman battering. Violence Against Women, 5(2), 134-154.

Edleson, J. L. (2004). Should childhood exposure to adult domestic violence be defined as child maltreatment under the law? In P. G. Jaffe, L. L. Baker \& A. Cunningham (Eds.), Protecting children from domestic violence: Strategies for community intervention (pp. 8-29). New York, NY: Guilford Press.

Fantuzzo, J., Boruch, R., Beriama, A., \& Atkins, M. (1997). Domestic violence and children: Prevalence and risk in five major U.S. cities. Journal of the American Academy of Child \& Adolescent Psychiatry, 36(1), 116-122.

Fantuzzo, J., \& Mohr, W. K. (1999). Prevalence and effects of child exposure to domestic violence. Future of Children, 9(3), 21-32.

Ferrari, A. M. (2002). The impact of culture upon child rearing practices and definitions of maltreatment. Child Abuse \& Neglect, 26, 793-813.

Findlater, J. E., \& Kelly, S. (1999). Child protective services and domestic violence. The Future of Children, 9(3), 84-96.

Harding, K., \& Fromm, S. (2000). Public opinion and behaviors regarding child abuse prevention: 2000 survey. Chicago: Prevent Child Abuse America. 
Hazen, A. L., Connelly, C. D., Kelleher, K., Landsverk, J., \& Barth, R. (2004). Intimate partner violence among female caregivers of children reported for child maltreatment. Child Abuse \& Neglect, 28(2004), 301-319.

Holden, G. W. (2003). Children exposed to domestic violence and child abuse: Terminology and taxonomy. Clinical Child and Family Psychology Review, 6(3), 151-160.

Imhof, L., Murphy, S. R., \& Moore, W. (2001). California vignettes study, methodology report. Chicago, IL: National Opinion Research Center, University of Chicago.

Kernic, M. A., Wolf, M. E., Holt, V. L., McKnight, B., Huebner, C. E., \& Rivara, F. P. (2003). Behavioral problems among children whose mothers are abused by an intimate partner. Child Abuse \& Neglect, 27(11), 1231-1246.

Kitzmann, K. M., Gaylord, N. K., Holt, A. R., \& Kenny, E. D. (2003). Child witnesses to domestic violence: A meta-analytic review. Journal of Consulting and Clinical Psychology, 71(2), 339-352.

Lin, T. E. (1999). Social norms and judicial decisionmaking: Examining the role of narratives in same-sex adoption cases. Columbia Law Review, 99(3), 739-794.

Magen, R. H. (1999). In the best interests of battered women: Reconceptualizing allegations of failure to protect. Child Maltreatment: Journal of the American Professional Society on the Abuse of Children, 42(2), 127-135.

Margolin, G., \& Gordis, E. B. (2000). The effects of family and community violence on children. Annual Review of Psychology, 51, 445-479.

McFarlane, J. M., Groff, J. Y., O'Brien, J. A., \& Watson, K. (2003). Behaviors of children who are exposed and not exposed to intimate partner violence: An analysis of 330 black, white, and Hispanic children. Pediatrics, 112(3), E202-E207.

McGuigan, W. M., \& Pratt, C. C. (2001). The predictive impact of domestic violence on three types of child maltreatment. Child Abuse \& Neglect, 25(7), 869-883. 
Patterson, C. J. (1995). Lesbian and gay parenting: A resource for psychologists. Retrieved October 11, 2004, from http://www.apa.org/pi/parent.html

Pedhazur, E. J., \& Kerlinger, F. N. (1982). Multiple regression in behavioral research: Explanation and prediction (2nd ed.). New York: Holt Rinehart and Winston.

Rose, S. J., \& Meezan, W. (1995). Child neglect: A study of the perceptions of mothers and child welfare workers. Children and Youth Services Review, 17, 471-486.

Rossi, P. H., \& Anderson, A. B. (1982). The factorial survey approach: An introduction. In P. H. Rossi \& S. L. Nock (Eds.), Measuring social judgments: The factorial survey approach (pp. 1567). Beverly Hills, CA: Sage.

Schechter, S., \& Edleson, J. L. (1999). Effective intervention in domestic violence and child maltreatment cases: Guidelines for policy and practice, Recommendations from the National Council of Juvenile and Family Court Judges. Retrieved December 29, 2004, from http://www.ncjfcj.org/publications/main.cfm?Action=PUBFILE\&PFileID=3

Sharwline Nicholson vs. Nicholas Scoppetta et al. (United States Court of Appeals for the Second Circuit 2004).

Sorenson, S. B. (2003). Funding public health: The public's willingness to pay for domestic violence prevention programming. American Journal of Public Health, 93(11), 1934-1938.

Sorenson, S. B., \& Taylor, C. A. (2003). Personal awareness of domestic violence: Implications for health care. Journal of the American Medical Women's Association, 58(1), 4-9.

Sorenson, S. B., \& Taylor, C. A. (2005). Female aggression toward male intimate partners: An examination of social norms in a community-based sample. Psychology of Women Quarterly, 29, 78-96.

Straus, M. A. (1992). Children as witnesses to marital violence: A risk factor for lifelong problems among a nationally representative sample of American men and women. In D. F. Schwarz (Ed.), Children and violence: Report of the 23rd Ross Roundtable on Critical Approaches to Common Pediatric Problems (pp. 98-109). Columbus, Ohio: Ross Laboratories. 
Taylor, C. A., \& Sorenson, S. B. (2004). Injunctive social norms of adults regarding teen dating violence. Journal of Adolescent Health, 34(6), 468-479.

Taylor, C. A., \& Sorenson, S. B. (2005). Community-based norms about intimate partner violence: Putting attributions of fault and responsibility into context. Sex Roles, 53(7/8), 573589.

Tuckel, P., \& O'Neill, H. (2001). The vanishing respondent in telephone surveys. Paper presented at the American Association for Public Opinion Research, Montreal.

U.S. Census Bureau, State and County QuickFacts: California. (2000). Retrieved March 14, 2003, from http://quickfacts.census.gov/qfd/states/06000.html

Weinbaum, Z., Stratton, T. L., Chavez, G., Motylewski-Link, C., Barrera, N., \& Courtney, J. G. (2001). Female victims of intimate partner physical domestic violence (IPP-DV), California 1998. American Journal Preventive Medicine, 21(4), 313-319.

Wolfe, D. A., Crooks, C. V., Lee, V., McIntyre-Smith, A., \& Jaffe, P. G. (2003). The effects of children's exposure to domestic violence: A meta-analysis and critique. Clinical Child and Family Psychology Review, 6(3), 171-187. 
Table 1. Proportion of Affirmative Responses to "Should social workers be called to check on the children?" for the Three Variables with the Widest Variation in Support $(\mathrm{n}=6,556)$

\begin{tabular}{lll}
\hline Variable & Percentage & p \\
\hline Abuse Type & & 0.000 \\
Beat up & 77.6 & \\
Forced to have sex & 75.7 & \\
Punched with fist & 70.7 & \\
Pressured to have sex & 70.3 & \\
Slapped & 67.6 & \\
Threatened to harm & 63.4 & 0.000 \\
Destroyed social security card and driver's license ${ }^{1}$ & 63.3 & \\
Belittled and insulted & 62.2 & \\
Could no longer have contact with anyone but assailant & & \\
Weapon & 78.5 & \\
Pulled out a gun & 75.5 & \\
Pulled out a knife & 69.8 & \\
Grabbed an available object in a threatening manner & 64.0 & \\
No weapon mentioned & & \\
Respondent Ethnicity & 81.3 & \\
Hispanic & 76.4 & \\
Other Asian American ${ }^{2}$ & 69.2 & \\
White & 65.0 & \\
African American & 64.4 & \\
Korean American & 62.3 & \\
Vietnamese American & & \\
\hline
\end{tabular}

${ }^{1}$ When the victim was "a recent immigrant," "social security card and driver's license" was replaced with "green card."

${ }^{2}$ Not of Korean or Vietnamese descent. 
Table 2. "Should social workers be called to check on the children?" Multivariate logistic regression findings $(\mathrm{n}=6,342)$

\begin{tabular}{|c|c|c|}
\hline & AOR & p-value \\
\hline \multicolumn{3}{|l|}{ Vignette Variables } \\
\hline \multicolumn{3}{|l|}{ Abuse type (vs. Belittled and insulted) } \\
\hline Beat up & 2.56 & $0.00000^{* * * *}$ \\
\hline Forced to have sex & 2.04 & $0.00000^{* * * *}$ \\
\hline Punched with fist & 1.86 & $0.00000^{* * * *}$ \\
\hline Slapped & 1.46 & $0.002 * *$ \\
\hline Pressured to have sex & 1.42 & $0.006^{* *}$ \\
\hline Threatened to harm & 1.25 & 0.06 \\
\hline Could no longer have contact with anyone but assailant & 0.89 & 0.36 \\
\hline Destroyed social security card and driver's license & 0.89 & 0.33 \\
\hline \multicolumn{3}{|c|}{ Weapon (vs. Grabbed an available object in a threatening manner) } \\
\hline Pulled out a gun & 2.11 & $0.00000 * * * *$ \\
\hline Pulled out a knife & 1.61 & $0.00001 * * * *$ \\
\hline No weapon mentioned & 0.68 & $0.002 * *$ \\
\hline \multicolumn{3}{|l|}{ Frequency of incident (vs. The only time) } \\
\hline The fifth time & 1.92 & $0.00000^{* * * *}$ \\
\hline One of many times & 1.73 & $0.00000^{* * * * *}$ \\
\hline \multicolumn{3}{|l|}{ Victim Gender/Sexual Orientation (vs. Female/Heterosexual) } \\
\hline Male/Homosexual & 1.76 & $0.0002 * * * *$ \\
\hline Female/Homosexual & 1.49 & $0.008 * *$ \\
\hline Male/Heterosexual & 0.92 & 0.36 \\
\hline \multicolumn{3}{|l|}{ Assailant Alcohol use (vs. Had nothing to drink) } \\
\hline Drank heavily & 1.46 & $0.001 * *$ \\
\hline Had 2 drinks & 1.24 & 0.06 \\
\hline \multicolumn{3}{|l|}{ Victim Alcohol use (vs. Had nothing to drink) } \\
\hline Drank heavily & 1.39 & $0.003 * *$ \\
\hline Had 2 drinks & 1.18 & 0.12 \\
\hline \multicolumn{3}{|l|}{ Assailant Ethnicity (vs. White) } \\
\hline African American & 0.69 & $0.03 *$ \\
\hline Latino & 0.70 & $0.04 *$ \\
\hline Asian American & 0.70 & $0.04 *$ \\
\hline Korean American & 0.71 & $0.02 *$ \\
\hline Vietnamese American & 0.80 & 0.21 \\
\hline \multicolumn{3}{|l|}{ Relationship status (vs. Married to) } \\
\hline Divorced from & 1.22 & $0.05 *$ \\
\hline Dating & 1.17 & 0.11 \\
\hline Separated from & 1.13 & 0.19 \\
\hline Living with & 1.05 & 0.61 \\
\hline
\end{tabular}




\begin{tabular}{lll}
\hline Respondent Characteristics & & \\
\hline Race/Ethnicity (vs. White) & & \\
Hispanic & 1.64 & $0.002^{* *}$ \\
Other Asian American & 1.17 & 0.33 \\
African American & 0.74 & $0.02^{*}$ \\
Korean American & 0.59 & $0.003^{* *}$ \\
Vietnamese American & 0.51 & $0.00016^{* * * *}$ \\
Gender & & \\
Male & 0.75 & $0.0002^{* * * *}$ \\
Country of Origin (vs. U.S.) & & \\
Outside of U.S. & 1.44 & $0.004^{* *}$ \\
Number of people supported on income (vs. 1) & & \\
2 & 1.39 & $0.009^{* *}$ \\
3 & 1.04 & 0.77 \\
4 & 1.10 & 0.53 \\
5 or more & 1.41 & $0.03^{*}$ \\
Current Relationship Status (vs. Married) & & \\
Dating & 1.50 & $0.02^{*}$ \\
Not currently in a relationship & 1.42 & $0.02^{*}$ \\
In serious relationship & 1.29 & 0.22 \\
Living with partner & 1.14 & 0.50 \\
Employment status (vs. Working full-time) & & \\
In school & 1.40 & $0.03^{*}$ \\
Retired & 1.38 & $0.02^{*}$ \\
Other & 1.35 & 0.25 \\
Unemployed & 1.14 & 0.44 \\
Working part-time & 1.04 & 0.72 \\
Keeping house & 0.93 & 0.62 \\
\hline
\end{tabular}

Note. The table includes all variables with statistically significant $(\mathrm{p}<0.05)$ adjusted odds ratios (AORs). The model also included other vignette variables (victim and assailant age, victim ethnicity, victim and assailant nativity, victim and assailant socioeconomic status, motivation for the abuse, and weapon placement in vignette), respondent characteristics (age, marital status, children in home, number of adults in home, education level, size of town, and income ), a "vignette order" variable, and a "personal awareness of a domestic violence victim" variable that were not statistically significant. A table that includes AORs for all variables included in the model is available upon requests from the authors. ${ }^{*} \mathrm{p}<0.05 ; * * \mathrm{p}<0.01 ; * * * \mathrm{p}<0.001 ; * * * *$ $\mathrm{p}<0.00044$ 